\title{
A Novel Configuration of A Microstrip Power Amplifier based on GaAs-FET for ISM Applications
}

\author{
Amine Rachakh ${ }^{1}$, Larbi El Abdellaoui ${ }^{2}$, Jamal Zbitou $^{3}$, Ahmed Errkik $^{4}$, Abdelali Tajmouati ${ }^{5}$, \\ Mohamed Latrach ${ }^{6}$ \\ 1,2,3,4,5 LMEET Laboratory FST of Settat Hassan 1st University, Morocco \\ ${ }^{6}$ Microwave Group ESEO Angers France
}

\section{Article Info}

Article history:

Received May 27, 2018

Revised Aug 28, 2018

Accepted Sep 6, 2018

\section{Keyword:}

Advanced design system

Field-effect transistor (FET)

Gallium arsenide (GaAs)

Matching network (MN)

Microstrip technology

Power amplifier (PA)

\begin{abstract}
Power Amplifiers (PA) are very indispensable components in the design of numerous types of communication transmitters employed in microwave technology. The methodology is exemplified through the design of a $2.45 \mathrm{GHz}$ microwave power Amplifier (PA) for the industrial, scientific and medical (ISM) applications using microstrip technology. The main design target is to get a maximum power gain while simultaneously achieving a maximum output power through presenting the optimum impedance which is characteristically carried out per adding a matching circuit between the source and the input of the power amplifier and between the load and the output of the power amplifier. A "T" matching technique is used at the input and the output sides of transistor for assure in band desired that this circuit without reflections and to obtain a maximum power gain. The proposed power amplifier for microwave ISM applications is designed, simulated and optimized by employing Advanced Design System (ADS) software by Agilent. The PA shows good performances in terms of return loss, output power, power gain and stability; the circuit has an input return loss of $-38 \mathrm{~dB}$ and an output return loss of $-33.5 \mathrm{~dB}$. The $1-\mathrm{dB}$ compression point is $8.69 \mathrm{dBm}$ and power gain of the PA is $19.4 \mathrm{dBm}$. The Rollet's Stability measure $\mathrm{B} 1$ and the stability factor $\mathrm{K}$ of the amplifier is greater than 0 and 1 respectively, which shows that the circuit is unconditionally stable. The total chip size of the PA is $73.5 \times 36 \mathrm{~mm}^{2}$.
\end{abstract}

Copyright @ 2018 Institute of Advanced Engineering and Science. All rights reserved.

Corresponding Author:

Amine Rachakh,

Faculty of Sciences and Techniques,

University Hassan 1st,

University Complex Casablanca road, Km 3.5, B.P: 577 Settat, Morocco.

Email: rachakh.amine1@gmail.com

\section{INTRODUCTION}

In RF and microwave wireless communication transmitter, power amplifier (PA) is the most important bloc which amplifies the RF signal to antenna and provides gain as high as possible with the lowest reflection possible.

The request for RF/microwave amplifier operates at high frequency has been raised too support high data rate wireless communication applications and many other applications such as radar system and satellite communications [1]-[4].

Latterly, several power amplifiers based on Gallium Arsenide (GaAs) technology were reported in the literature [5]-[9]. The GaAs technology is usually selected due to its capabilities to produce high gain and high output power.

The ISM band microwave amplifiers has become very mostly and popular used for wireless applications by dint of its characteristics of high speed and high data rate with low power dissipation. 
Recently [10], [11], many researchers contacted study in designing and developing microwave amplifier but most of the reported power amplifier has been implemented for low frequency.

This work proposes a novel and a simple power amplifier architecture is intended for applications ISM at 2.45GHz. This power amplifier consists of a Gallium Arsenide Field-effect transistor (GaAs FET) technology. To improve circuit performance, the mirostrip lines technology will be used. A " $T$ " type matching is used at the input and the output side of transistor for assure in band desired that this circuit without reflections and to obtain a maximum power gain. This PA is printed on an FR4 substrate having the following specification: a relative permittivity $=4.4$, a tangent loss $\tan ()=0.025$, a metallization thickness $\mathrm{t}=0.035 \mathrm{~mm}$ and a substrate thickness $\mathrm{h}=1.6 \mathrm{~mm}$.

The result of the work is organized as follows: Section 2 introduces the theoretical aspects while Section 3 presents design procedure of proposed PA in detail, the simulation results including a discussion is presented in Section 4 and lastly, Section 5 offers the conclusion.

\section{THEORETICAL ASPECTS}

Fundamentally, for the concept of an amplifier, the input and output matching network are designed to carry out the required small signal gain, stability, and bandwidth. Hyper-frequency amplifier is a typical active circuit utilized to amplify the amplitude of RF signal. Basic concept and consideration in design of hyper frequency amplifier is presented below. For the power amplifier designed, the expression and equation were referred to [12]-[17]. Figure 1, presents a typical single-stage microwave amplifier with an input/output matching networks.

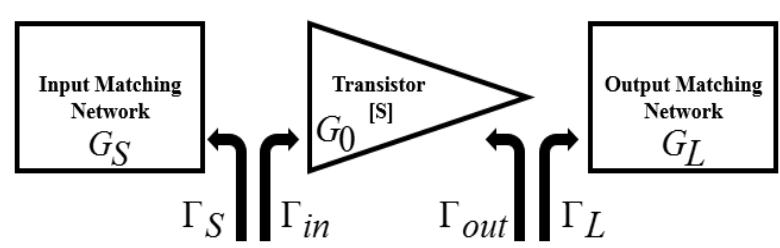

Figure 1. Block diagram of power amplifier

Where:

The reflection coefficient of the source:

$$
\Gamma_{S}=\frac{Z_{S}-Z_{0}}{Z_{S}+Z_{0}}
$$

The reflection coefficient of the load:

$$
\Gamma_{L}=\frac{Z_{L}-Z_{0}}{Z_{L}+Z_{0}}
$$

The input reflection coefficient:

$$
\Gamma_{I N}=\frac{Z_{I N}-Z_{0}}{Z_{I N}+Z_{0}}=S_{11}+\frac{S_{12} S_{21} \Gamma_{L}}{1-S_{22} \Gamma_{L}}
$$

The output reflection coefficient:

$$
\Gamma_{\text {oUT }}=\frac{Z_{\text {OUT }}-Z_{0}}{Z_{\text {OUT }}+Z_{0}}=S_{22}+\frac{S_{12} S_{21} \Gamma_{S}}{1-S_{11} \Gamma_{S}}
$$


The key concept of microwave power amplifier design is to match input/output networks of a transistor at hyper-frequencies utilizing scattering-parameters frequency characteristics at a specific DC-bias point with source and load impedances. Matching networks circuit is essential to ameliorate efficiency of transmission from source to load and to minimize undesirable reflection of signal [12] and [14].

\subsection{Condition for matching}

The scattering parameters of transistor were determined. The merely flexibility permitted to the designer is the network matching circuit. The input circuit should match to the source while the output circuit should match to the load for to transfer maximum power to the load. After stability condition of active device is achieved, network matching circuits should be designed in order that reflection coefficient of every port can be correlated with conjugate complex number as defined below [15]:

$$
\begin{gathered}
\Gamma_{I N}=\Gamma_{S}^{*}=S_{11}+\frac{S_{12} S_{21} \Gamma_{L}}{1-S_{22} \Gamma_{L}} \\
\Gamma_{\text {oUT }}=\Gamma_{L}^{*}=S_{22}+\frac{S_{12} S_{21} \Gamma_{S}}{1-S_{11} \Gamma_{S}}
\end{gathered}
$$

\subsection{Stability condition}

Stability condition is a great attention in RF/Microwave amplifier designing. It have be stabilized by attenuating any oscillations that may happen and damage the amplifier. Stability has been established by deriving the selected scattering-parameters and calculating the stability factor $(\mathrm{K})$ and stability measure (B1) using equations (7) and (8) .the microwave amplifier will be unconditionally stable if the k-factor is greater than unity $(\mathrm{K}>1)$ and the $\mathrm{B} 1$-factor is greater than zero $(\mathrm{B} 1>0)$, and if the $\mathrm{K}$ is less than unity and B1 less than zero, the microwave amplifier would be conditionally stable and plotting stable circle in smith chart is needed to determine in which region the amplifier is not stable to avoid oscillation condition [16] and [17]. By using the Rollelt's condition that is given as:

$$
\begin{aligned}
& k=\frac{1-\left|\mathrm{S}_{11}\right|^{2}-\left|\mathrm{S}_{22}\right|^{2}+|\Delta|^{2}}{2\left|\mathrm{~S}_{12} \mathrm{~S}_{21}\right|}>1 \\
& B_{1}=1+\left|\mathrm{S}_{11}\right|^{2}-\left|\mathrm{S}_{22}\right|^{2}-|\Delta|^{2}>0 \\
& |\Delta|=\left|\mathrm{S}_{11} \mathrm{~S}_{22}-\mathrm{S}_{12} \mathrm{~S}_{21}\right|
\end{aligned}
$$

Where

$\mathrm{K}$ is the Rolett factor.

$\mathrm{B}_{1}$ is the Stability measure

\subsection{Power gain}

A single-stage microwave PA "Power Amplifier" can be modeled by the circuit of Figure 1, where matching networks are used on both sides of the transistor to transform the input and output impedance $Z_{0}$ to the source impedance $Z_{S}$ and load impedance $Z_{L}$. Various power gains were defined for to comprehend operation of microwave amplifier, power gains are classified into Operating Power Gain, Available Power Gain and Transducer Power Gain [14].

\subsubsection{Operating power gain}

Operating Power Gain is the ratio of power dissipated in the load $\mathrm{Z}_{\mathrm{L}}$ to the power delivered to the input of the 2-port network. This gain is independent of $Z_{S}$, although the characteristics of some active 
devices may be dependent on $Z_{S}$ [13], [14]. Operating Power Gain is given by:

$$
G_{P}=\frac{P_{L}}{P_{I N}}=\frac{1}{1-\left|\Gamma_{I N}\right|^{2}}\left|S_{21}\right|^{2} \frac{1-\left|\Gamma_{L}\right|^{2}}{\left|1-S_{22} \Gamma_{L}\right|^{2}}
$$

Where:

$\mathrm{P}_{\mathrm{L}}$ : Power delivered to the load

$\mathrm{P}_{\mathrm{IN}}$ : Power input to the network

\subsubsection{Available power gain}

Available Power Gain is the ratio of the power available from the 2-port network to the power available from the source. This assumes conjugate matching of both the source and the load, and depends on $\mathrm{Z}_{\mathrm{S}}$, but not $\mathrm{Z}_{\mathrm{L}}[14]$. Available Power Gain is defined by:

$$
G_{A}=\frac{P_{a v n}}{P_{a v s}}=\frac{1-\left|\Gamma_{S}\right|^{2}}{\left|1-S_{11} \Gamma_{S}\right|^{2}}\left|S_{21}\right|^{2} \frac{1}{\left|1-S_{22} \Gamma_{L}\right|^{2}}
$$

Where:

$$
\mathrm{P}_{\mathrm{avn}} \text { : Power available from the network }
$$

$\mathrm{P}_{\mathrm{avs}}$ : Power available from the source

\subsubsection{Transducer power gain}

Transducer Power Gain is the ratio of the power delivered to the load to the power available from the source. This depends on both $Z_{S}$ and $Z_{L}$ [14]. Transducer Power Gain is expressed by:

$$
G_{T}=\frac{P_{L}}{P_{a v s}}=\frac{1-\left|\Gamma_{S}\right|^{2}}{\left|1-S_{S} \Gamma_{I N}\right|^{2}}\left|S_{21}\right|^{2} \frac{1-\left|\Gamma_{L}\right|^{2}}{\left|1-S_{22} \Gamma_{L}\right|^{2}}
$$

The transducer power gain is the most useful gain definition for amplifier design, which accounts for both source and load mismatch.

\section{DESIGN PROCEDURE}

Gallium Arsenide Field Effect Transistor (GaAs FET) technologies have been chosen to be utilized for the proposed ISM-band microwave amplifier due to its performance in UHF range and it's become an excellent choice for high frequency circuit and it meets the required specifications of the proposed ISM-band microwave amplifier. DC-biasing voltage and current circuit have been designed based on the data sheet of ATF-21170 which biased at $\mathrm{V}_{\mathrm{DS}}=4 \mathrm{v}$ and $\mathrm{I}_{\mathrm{ds}}=50 \mathrm{~mA}$.

DC-biasing circuits consist of Radial stub directly after a quarter-wavelength line $(\lambda / 4)$ add at the Drain and at the Gate, this Biasing circuit will help to achieve proper isolation at desired RF frequency and to play the role of an RF choke. The capacitors at input/output ports are utilized as DC blocking capacitors [18]. All capacitors value have been tuned to meet the available commercial at the market, along with different capacitors used in the proposed amplifier in Table 1. At the source paths, a Taper line was added in series to improve the stability. The PA requires both input and output matching network. The matching networks provides matching impedances by microstrip transmission lines technology. It is well known that the impeccable matching of an amplifier is gotten only when the amplifier is matched for maximum power gain with a narrow bandwidth. However, in the design of power amplifiers, good matching is preferred rather than maximum high gain just as the stability should be achieved in the design of PAs. Moreover the impedance matching will not be excellent when the power gain is in extreme condition somewhat inherently in the single stage topology. In order to overcome this problem and get the good matching with high power gain. A "T" type matching is used at the input and the output side of transistor. The detailed Circuitry of the proposed 
design is represented in the Figure 2. The printed circuit of the ISM power amplifier were implemented in microstrip technology using Epoxy substrate (FR4) with a relative permittivity of 4.4, a thickness of $1.6 \mathrm{~mm}$, a metallization thickness $t=0.035 \mathrm{~mm}$ and a tangential loss of 0.025 . For more realizable results, Momentum tool is performed. Layout architecture utilized for to show the location of the components and the real circuit size. The layout of the final proposed power amplifier structure is illustrated in Figure 3, where the overall size of this power amplifier is $73.5 \mathrm{~mm}(\mathrm{~L}) * 36 \mathrm{~mm}(\mathrm{~W})$.

Table 1. Different Capacitors used in the Proposed Power Amplifier

\begin{tabular}{ll}
\hline Capacitors & Values $(\mathrm{pF})$ \\
\hline $\mathrm{C}_{\text {in }}$ & 220 \\
$\mathrm{C}_{\text {out }}$ & 220 \\
$\mathrm{C}_{\text {D_Bias }}$ & 220 \\
$\mathrm{C}_{\mathrm{G} \_ \text {Bias }}$ & 220 \\
\hline
\end{tabular}

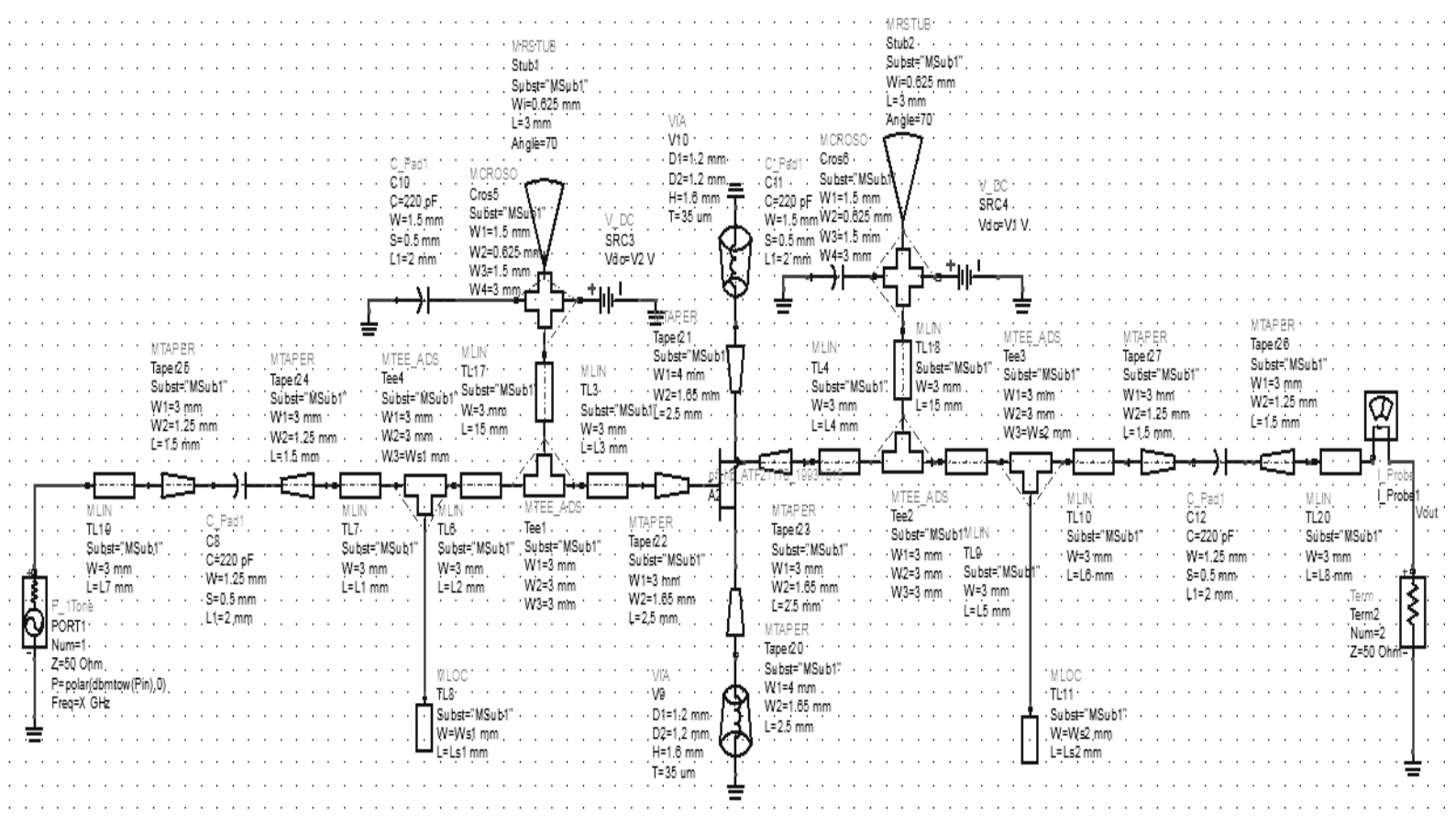

Figure 2. Topology of the proposed amplifier designed with a " $T$ " type matching

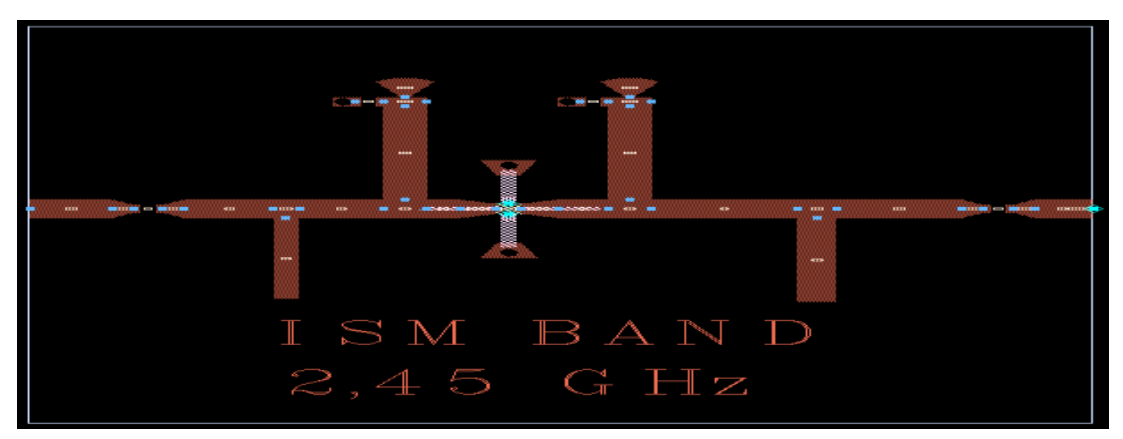

Figure 3. Layout of the proposed amplifier 


\section{SIMULATION RESULTS AND DISCUSSION}

The DC voltage of power amplifier is adjusted to $\mathrm{V}_{\mathrm{DS}}=4 \mathrm{~V}$ and $\mathrm{V}_{\mathrm{GS}}=0.5 \mathrm{~V}$.during the simulation, optimization technique was used to get better performance and to reduce the size of power amplifier. The proposed microwave power amplifier was characterized by small signal performance and power performance simulations.

Both small signal performance and power performance simulations have been executed using the advanced Design System (ADS) software.

Small-signal simulations are performed using an S-parameters which run from 2 to $3 \mathrm{GHz}$. Figure 4 presents the simulated small-signal of performance of the proposed microwave power amplifier. the small signal performance shows the power gain of this power amplifier is about $19.4 \mathrm{~dB}$ with an isolation coefficient (S12) lower than $-24 \mathrm{~dB}$ over the bandwidth, and the return loss is lesser than $-10 \mathrm{~dB}$ over the interested band; it can be observed that the input return loss (S11) is less than $-38 \mathrm{~dB}$ and the output return loss (S22) is less than $-33.5 \mathrm{~dB}$ at $2.45 \mathrm{GHz}$. The stability condition of this power amplifier is determined through small-signal performance, According to the Rolett Criteria. The necessary and adequate conditions for unconditional stability are determined by the Equations (7), (8). From figures below, it can be seen that B1>0 and K >1 over operating frequency band. Consequently, the conditions for unconditional stability of proposed power amplifier are confirmed on the interested band, which means there is no risk of oscillations. Figure 5 and Figure 6 illustrates the curves of the stability measure B1 and the stability factor K versus frequency.

The power performance (the large-signal performance) is simulated using a Harmonic Balanced simulator. This PA was run at the frequency of $2.45 \mathrm{GHz}$ for power input range from -30 to $30 \mathrm{dBm}$ under $\mathrm{V}_{\mathrm{DS}}=4 \mathrm{~V}$ supply voltage. The circuit achieves a maximum saturated output power of $8 \mathrm{dBm}$ at $1 \mathrm{~dB}$ compression point. Figure 7 shows the simulation results of output power versus input power at the frequency of $2.45 \mathrm{GHz}$.

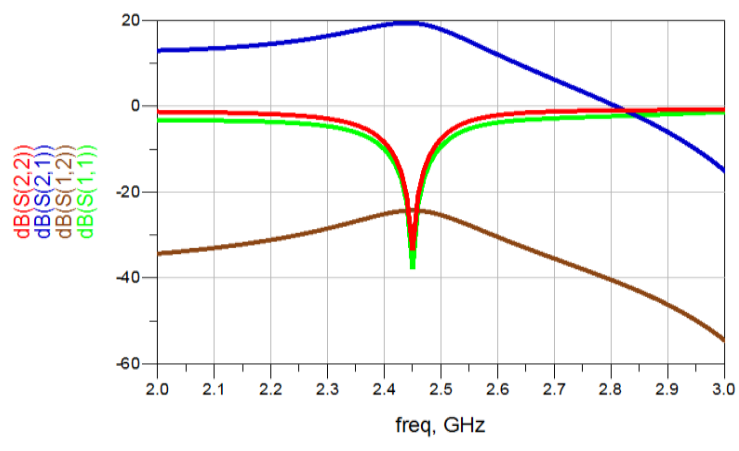

Figure 4. S-parameters versus frequency of the proposed ISM-amplifier

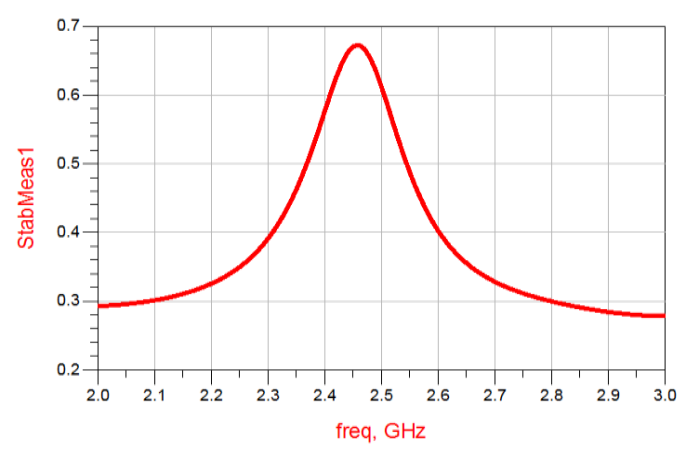

Figure 6. Stability measure versus frequency characteristics

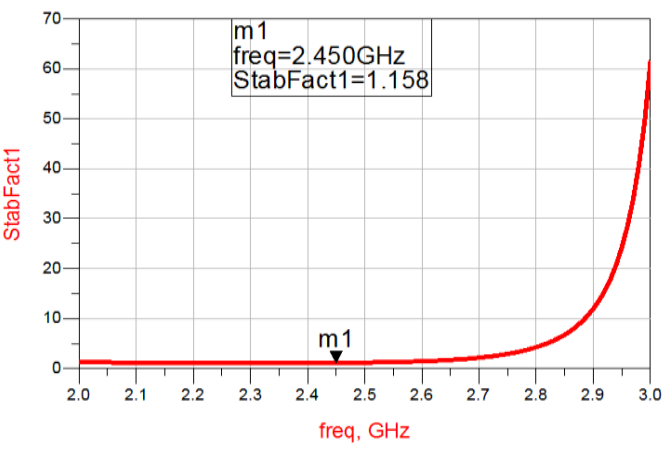

Figure 5. Stability factor versus frequency characteristics

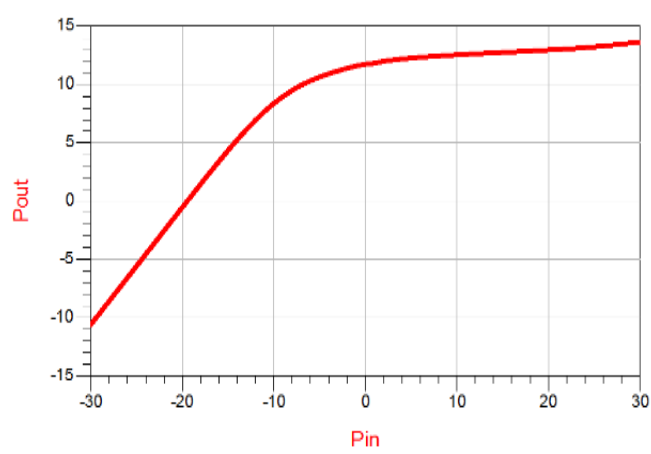

Figure 7. Input power versus output power for $2.45 \mathrm{GHz}$

The proposed power amplifier performances were compared to some existing works in the literature in terms of Power Gain and Reflection Coefficients, the comparison results are presented in Table 2, we can conclude that the proposed amplifier has a excellent performances compared to the reported works. 
Table 2. Comparison of Proposed Power Amplifier Performance with some Existing PAs

\begin{tabular}{ccccccc}
\hline Ref & Technology & $\begin{array}{c}\text { Frequency } \\
(\mathrm{GHz})\end{array}$ & $\begin{array}{c}\text { Supply Voltage } \\
(\mathrm{V})\end{array}$ & $\begin{array}{c}\text { Power Gain } \\
(\mathrm{dB})\end{array}$ & $\begin{array}{c}\text { Input Return } \\
\text { Loss }(\mathrm{dB})\end{array}$ & $\begin{array}{c}\text { Output Return } \\
\text { Loss }(\mathrm{dB})\end{array}$ \\
\hline$[18]$ & Si BJT & $1.7-2.2$ & 10 & $11.5 \pm 1$ & -22 & -24 \\
{$[19]$} & PHEMT & 1.9 & 4.75 & 13 & -15 & - \\
{$[20]$} & GaAs PHEMT & 2.45 & 3 & 7.51 & -7.49 & -10.95 \\
{$[21]$} & 180nm CMOS & 2.45 & 1.8 & 15 & -12.66 & -17 \\
{$[22]$} & GaN HEMT & $1.9-2.5$ & 28 & 15.9 & -10 & -15.8 \\
{$[23]$} & SiGe HBT & 2.4 & 2.75 & 19.4 & -38 & -33.5 \\
This Work & GaAs FET & 2.45 & 4 & & & \\
\hline
\end{tabular}

\section{CONCLUSION}

This paper presents a new design of microwave single stage power amplifier intended for applications ISM at $2.45 \mathrm{GHz}$. This is performed by employing a GaAs FET (ATF-21170). The aim of this manuscript is design, simulate and optimize a microwave power amplifier with a microstrip technology. The use of T matching technique at the input and the output stages of the PA has contributed the best performance for the amplifier. From the design parameters and simulation result. The proposed PA is biased at supply voltage of VDS $=4 \mathrm{~V}$ with drain current of $50 \mathrm{~mA}$. The microwave power amplifier has an isolation coefficient (S12) lower than $-24 \mathrm{~dB}$ with a power gain of $19 \mathrm{~dB}$, input return loss of $-38 \mathrm{~dB}$ and output return loss of $-33.5 \mathrm{~dB}$ and stability without oscillating in its required frequency band.

\section{ACKNOWLEDGEMENTS}

The authors would like to take this opportunity to thank Mr. Mohamed Latrach Professor in ESEO, engineering institute in Angers, France, for allowing us to use electromagnetic solvers available in his laboratory.

\section{REFERENCES}

[1] F. Oktafiani, et al., "Measurement and Evaluation of Tx/Rx Antennas for X-Band Radar System", TELKOMNIKA (Telecommunication Comput. Electron. Control. vol. 14, no. 2, pp. 555-562, 2016.

[2] T. Van Hoi, et al., "Design of a Front-End for Satellite Receiver", International Journal of Electrical and Computer Engineering (IJECE), vol. 6, no. 5, p. 2282, 2016.

[3] T. K. Quach, et al., "Ultrahigh-efficiency Power Amplifier for Space Radar Applications", IEEE J. Solid-State Circuits, vol. 37, no. 9, pp. 1126-1134, 2002.

[4] S. Rezanezhad, "Design of Fuzzy Optimized Controller for Satellite Attitude Control by Two State actuator to reduce Limit Cycle based on Takagi-Sugeno Method", International Journal of Electrical and Computer Engineering (IJECE), vol. 4, no. 3, p. 303, 2014.

[5] W. R. Curtice and M. Ettenberg, "A Nonlinear GaAs FET Model for use in the Design of Output Circuits for Power Amplifiers”, IEEE Trans. Microw. Theory Tech., vol. 33, no. 12, pp. 1383-1394, 1985.

[6] C. Duvanaud, et al., "High-efficient Class F GaAs FET Amplifiers Operating with very low bias Voltages for use in Mobile Telephones at $1.75 \mathrm{GHz}$ ", IEEE Microw. Guid. Wave Lett, vol. 3, no. 8, pp. 268-270, 1993.

[7] A. Materka and T. Kacprzak, "Computer Calculation of large-signal GaAs FET Amplifier Characteristics", IEEE Trans. Microw. Theory Tech., vol. 33, no. 2, pp. 129-135, 1985.

[8] R. S. Pengelly and J. A. Turner, "Monolithic Broadband GaAs FET Amplifiers", Electron. Lett. vol. 12, no. 10, pp. 251-252, 1976.

[9] E. T. Watkins, et al., “A 60 GHz GaAs FET Amplifier,” in 1983 IEEE MTT-S Digest, 1983, pp. 145-147.

[10] P. B. Khannur, "A CMOS Power Amplifier with Power Control and T/R switch for 2.45-GHz Bluetooth/ISM band Applications", in Radio Frequency Integrated Circuits (RFIC) Symposium, 2003 IEEE, 2003, pp. 145-148.

[11] B. Tuch, "Development of WaveLAN®, an ISM band wireless LAN", Bell Labs Tech. J., vol. 72, no. 4, pp. 27-37, 1993.

[12] Inder J. Bahl, Fundamentals of RF and Microwave Transistor Amplifiers, 2009.

[13] Guillermo Gonzalez, "Microwave Transistor Amplifiers", Second Edition, Prentice Hall, Inc, 1997, 1984.

[14] David M. Pozar, "Microwave Engineering", Second Edition, University of Massachusetts at Amherst, John Wiely \& Sons, Inc., 1998.

[15] A. R. Othman, et al., "High Gain Cascaded Low Noise Amplifier Using T-Matching Network", J. Telecommun. Electron. Comput. Eng., vol. 2, no. 1, pp. 63-69, 2010.

[16] G. Su, et al., "An Estimable Stability Method Applied to Power Amplifier Design", in Electrical Design of Advanced Packaging and Systems Symposium (EDAPS), 2011 IEEE, 2011, pp. 1-4.

[17] E. L. Tan, et al., "Geometrical Stability Criteria for two-port Networks in Invariant Immittance Parameters Representation", in Microwave Conference, 2008. APMC 2008. Asia-Pacific, 2008, pp. 1-4. 
[18] A. Rachakh, et al., "A Novel Design of a Microstrip Microwave Broadband Power Amplifier for DCS, PCS and UMTS Bands", in Wireless Technologies, Embedded and Intelligent Systems (WITS), 2017 International Conference on, 2017, pp. 1-5.

[19] F. Y. Ng-Molina, et al., "Band-pass Distributed Power Amplifier in Monolithic Technology for the LTE Band", in Integrated Nonlinear Microwave and Millimetre-Wave Circuits (INMMIC), 2012 Workshop on, 2012, pp. 1-3.

[20] A. Rasmi, et al., “A 2.4 GHz Packaged Power Amplifier using GaAs PHEMT Technology”, in Micro and Nanoelectronics (RSM), 2011 IEEE Regional Symposium on, 2011, pp. 148-151.

[21] Santosh B. Patil and Rajendra D. Kanphade, "Design and Analysis of A 2.4 Ghz Fully Integrated 1.8V Power Amplifier in TSMC 180nm CMOS RF Process for Wireless Communication", International Conference on VLSI Systems, Architecture, Technology and Applications, 2015.

[22] M. Iqbal and A. Piacibello, "A 5W Class-AB Power Amplifier based on a GaN HEMT for LTE Communication Band", in Microwave Symposium (MMS), 2016 16th Mediterranean, 2016, pp. 1-4.

[23] P. Saad and N. B. Carvalho, "Power Amplifier Design for $2.4 \mathrm{GHz}, 802.11 \mathrm{~b}$ Standard using SiGe HBTTechnology", in 6th Conference on Telecommunications (Conftele 2007), Portugal, 2007, pp. 9-11.

\section{BIOGRAPHIES OF AUTHORS}
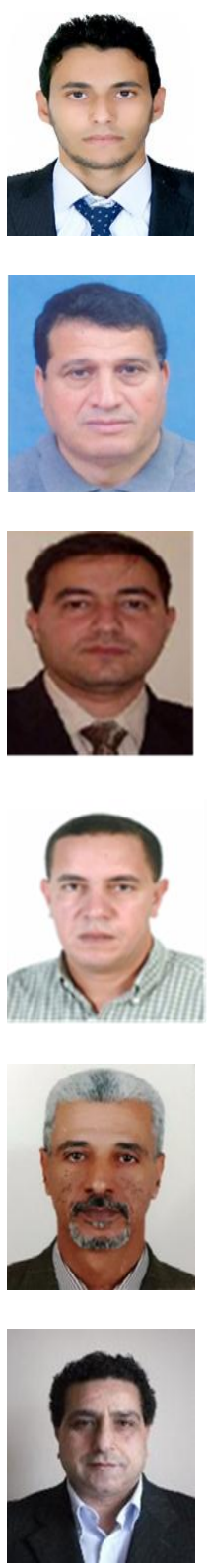

Amine Rachakh was born in Youssoufia, Morocco, in June 1990. He received the Master's degree in Microelectronics and Embedded Systems from the Faculty of Science Dhar El Mahrez, University Sidi Mohamed Ben Abdellah, Fes, Morocco, in 2014. He is currently prepared a Ph.D. degree in RF/Microwave and Electronics at Faculty of Sciences and Techniques, University Hassan 1st, Settat, Morocco, since 2015. His research interests include the study, design and realization of microwave power amplifiers.

Larbi El Abdellaoui was born in Tiflet, Morocco, in 1961. He received the Ph.D. degree in electronics from the University of Metz, in 1994, France. He is currently an associate Professor of Electronics in Faculty of sciences and techniques, University Hassan 1st, Settat, Morocco. He is involved in the design of hybrid, monolithic active and passive microwave electronic circuits

Jamal Zbitou was born in Fes, Morocco, in June 1976. He received the Ph.D. degree in electronics from Polytech of Nantes, the University of Nantes, Nantes, France, in 2005. He is currently an associate Professor of Electronics in FST University Hassan 1st, Settat, Morocco. He is involved in the design of hybrid, monolithic active and passive microwave electronic circuits.

Ahmed Errkik was born in July 1960 in Morocco. He received the Ph.D. degree in physics from the University of Technology Compiegne (UTC), France. He is currently an associate Professor of physics in FST University Hassan 1st, Settat, Morocco. He is involved in the design of hybrid, monolithic active and passive microwave electronic circuits.

\begin{abstract}
Abdelali Tajmouati was born in, Morocco, in 1962. He received the Ph.D. degree in science engineering from the University of Perpignan, France, in 1992. He is currently an associate Professor of Electronics, thermal transfer and thermodynamic in Faculty of sciences and techniques University Hassan 1st, Settat, Morocco. He is involved in the design of hybrid, monolithic active and passive microwave electronic circuits.
\end{abstract}

Mohamed Latrach was born in Douar Ksiba, Sless, Morocco, in 1958. He received the Ph.D. degree in electronics from the University of Limoges, Limoges, France, in 1990. He is currently a Professor of microwave engineering with the Ecole Suprieure d'Electronique de l'Ouest (ESEO), Angers, France, where his research involves RF and microwaves. His field of interest is the design of hybrid, monolithic active, and passive microwave circuits, metamaterials, LH materials, antennas and their applications in wireless Communications. 